\title{
ANALISIS PENGARUH PENYEMBUHAN LUKA PERINEUM PADA IBU NIFAS DI PUSKESMAS PANGARENGAN (Kecamatan Pangarengan Kabupaten Sampang)
}

\author{
Rikhly Faradisy Mursyida \\ Dosen AKBID Graha Husada Sampang \\ Email :decchi_87@yahoo.co.id
}

\begin{abstract}
ABSTRAK
Salah satu penyebab morbiditas dan mortalitas pada masa ibu nifas adalah infeksi pada masa nifas, dimana infeksi tersebut berawal dari luka perineum atau rupture perineum. Rupture perineum dapat terjadi karena adanya ruptur spontan maupun episiotomi perineum yang dilakukan atas indikasi antara lain: bayi besar, perineum kaku, persalinan yang kelainan letak, persalinan dengan menggunakan alat baik forceps atau vacum. Tujuan penelitian menganalisis faktor-faktor yang mempengaruhi dalam penyembuhan luka perineum pada ibu nifas di Puskesmas Pangarengan.

Desain penelitian meggunakan survey analitik dengan pendekatan cross sectional. Populasi sejumlah 35 ibu nifas. Variabel independen adalah faktor pengetahuan, status gizi, pendapatan, usia dan personal hygiene dengan variabel dependen adalah penyembuhan luka perineum. Pengumpulan data dengan kuesioner. Analisa data menggunakan kolerasi Spearman Rank.

Hasil penelitian menunjukkan pengetahuan ibu nifas baik rata-rata sebanyak 22 orang $(62,9 \%)$, hampir setengah status gizi ibu nifas normal sebanyak 16 orang $(45,7 \%)$, sebagian besar status sosial ekonomi (pendapatan) antara Rp.100.000-500.000 sebanyak 30 orang (85,7\%), hampir setengah usia ibu nifas antara 20-30 tahun sebanyak 16 orang (45,7\%), rata-rata yang mempunyai personal hygiene baik sebanyak 24 orang $(68,6 \%)$. Hasil penelitian didapatkan nilai pengetahuan $(p=0,216)$, status gizi $(p=0,717)$, pendapatan $(p=0,376)$, usia $(p=0,185)$, personal hygiene $(\mathrm{p}=0,000)$. Jadi yang mempengaruhi penyembuhan luka perineum adalah personal hygiene. Rata-rata pada ibu nifas dengan personal hygiene baik, penyembuhan luka perineumnya baik. Upaya yang dilakukan untuk penyembuhan luka perineum dengan memberi konseling atau penyuluhan tentang penyembuhan luka perineum
\end{abstract}

Kata Kunci: Penyembuhan luka perineum, Ibu Nifas

\section{PENDAHULUAN}

Salah satu penyebab morbiditas dan mortalitas pada masa ibu nifas adalah infeksi pada masa nifas dimana infeksi tersebut berawal dari luka perineum atau rupture perineum. Rupture perineum dapat terjadi karena adanya rupture spontan maupun episiotomi perineum yang dilakukan atas indikasi antara lain: bayi besar, perineum kaku, persalinan yang kelainan letak, persalinan dengan menggunakan alat baik forceps maupun vacum. Karena apabila episiotomi itu tidak dilakukan atas indikasi dalam keadaan yang tidak perlu dilakukan dengan indikasi di atas, maka menyebabkan peningkatan kejadian dan beratnya kerusakan pada daerah perineum yang lebih berat (Prawirohardjo, 2005).

Data di Puskesmas Pangarengan Januari 2014 diperoleh data jumlah ibu nifas 40 orang, dengan robekan perineum karena 
rupture sebanyak 12 orang $(30 \%)$, robekan perineum karena tindakan episiotomi, sebanyak 19 orang (47,5\%), dan perineum utuh sebanyak 9 orang (22,5\%). Berdasarkan survei awal ibu nifas dari 5 yang luka perineum proses penyembuhannya kurang baik karena ibu makan hanya dengan tahu dan tempe, ibu juga ada pantangan makanan seperti ikan, telor, daging, minumnya sedikit, mobilisasinya kurang baik sehingga dapat menghambat proses penyembuhan luka perineum.

Luka pada perineum akibat episiotomi, rupture, atau laserasi merupakan daerah yang tidak mudah untuk dijaga agar tetap bersih dan kering. Pada masa nifas, seorang ibu akan rentan terhadap infeksi. Untuk itu, menjaga kebersihan sangat penting untuk mencegah infeksi (Bahiyatun, 2009). Setelah buang air besar atau buang air kecil perineum dibersihkan secara rutin. Caranya yaitu dibersihkan dengan air hangat atau air bersih dan kassa steril (Uliyah, 2008). Sebelum dan sesudah membersihkan genetalia, ibu harus mencuci tangan sampai bersih. Pada waktu mencuci luka (episiotomi), ibu harus mencucinya dari arah depan ke belakang dan mencuci daerah anusnya yang terakhir (Bahiyatun, 2009). Jika dilakukan perawatan pada luka perineum post episiotomi maka akan mempercepat penyembuhan, sedangkan jika tidak dilakukan perawatan maka akan menyebabkan terjadinya infeksi (Ambarwati dan Wulandari, 2010).
Pada ibu nifas yang terjadi luka perineum, penyembuhannya dapat dipengaruhi oleh beberapa faktor diantaranya yaitu: faktor eksternal (status gizi, lingkungan, tradisi, pengetahuan, sosial ekonomi, penanganan petugas) dan faktor internal (usia, penanganan jaringan, hipovolemia, faktor lokal edema, personal hygiene, medikasi, aktifitas yang berlebih, penyakit penyerta) (Smeltzer, 2002).

Tujuan penelitian ini adalah menganalisis pengaruh penyembuhan luka perineum pada ibu nifas di Puskesmas Pangarengan Kec. Pengarengan Kab. Sampang.

\section{METODE PENELITIAN}

Desain penelitian ini adalah penelitian survey analitik korelasi rank spearman yang bersifat kuantitatif dengan pendekatan waktu cross sectional dimana pengumpulan semua variabel dilakukan pada satu saat. Metode sampling yang digunakan dalam penelitian ini adalah simple random sampling. Variabel dalam penelitian ini adalah : pengetahuan, status gizi, pendapatan, usia, personal hygiene serta penyembuhan luka perineum. Pengumpulan data dalam penelitian ini diperoleh dari data primer dengan kuesioner pada responden terhadap penyembuhan luka perinuem ibu nifas dan data sekunder telaah dokumen. Pengolahan dan analisis data dilakukan dengan editing, coding, scoring dan tabulating, uji regresi logistik ganda. 


\section{HASIL PENELITIAN}

\section{Analisis Univariat}

Tabel 1 Distribusi Frekuensi Ibu Berdasarkan Pengetahuan di Puskesmas Pangarengan BulanMei Tahun 2014.

\begin{tabular}{lcc}
\hline Pengetahuan & Frekuensi & Persentase (\%) \\
\hline $\begin{array}{l}\text { Pengetahuan } \\
\text { Kurang }\end{array}$ & 3 & 8,6 \\
\hline $\begin{array}{l}\text { Pengetahuan } \\
\text { cukup }\end{array}$ & 10 & 28,6 \\
\hline $\begin{array}{l}\text { Pengetahuan } \\
\text { Baik }\end{array}$ & 22 & 62,9 \\
\hline \multicolumn{1}{c}{ Total } & $\mathbf{3 5}$ & $\mathbf{1 0 0}$ \\
\hline
\end{tabular}

Pada tabel 1 didapatkan ibu nifas sebagian besar pengetahuan baik sebanyak 22 orang $(62,9 \%)$ dan paling sedikit yaitu pengetahuan kurang sebanyak 3 orang $(8,6 \%)$.

Tabel 2 Distribusi Frekuensi Ibu Berdasarkan Status Gizi di Puskesmas Pangarengan Bulan Mei Tahun 2014.

\begin{tabular}{lcc}
\hline Status Gizi & Frekuensi & Persentase \\
\hline Sangat kurus & 1 & 2,9 \\
\hline Kurus & 5 & 14,3 \\
\hline Normal & 22 & 62,8 \\
\hline Gemuk & 4 & 11,4 \\
\hline Sangat Gemuk & 3 & 8,6 \\
\hline \multicolumn{1}{c}{ Total } & $\mathbf{3 5}$ & $\mathbf{1 0 0}$
\end{tabular}

Berdasarkan tabel 2, menunjukkan normal sebanyak 22 orang $(62,8 \%)$ dan sebagian kecil ibu status gizinya sangat kurus sebanyak 1 orang (2,9\%).

Tabel 3 Distribusi Frekuensi lbu Berdasarkan Pendapatan di Puskesmas Pengarengan Bulan Mei Tahun 2014 bahwa status gizi ibu sebagian besar

\begin{tabular}{lcc}
\hline Status Ekonomi & Frekuensi & $\begin{array}{c}\text { Persentase } \\
(\%)\end{array}$ \\
\hline$<$ Rp. 100.000 & 1 & 2,9 \\
\hline $\begin{array}{l}\text { Rp. } 100.000- \\
500.000\end{array}$ & 30 & 85,7 \\
\hline$>$ Rp. 500.000 & 4 & 11,4 \\
\hline Total & $\mathbf{3 5}$ & $\mathbf{1 0 0}$ \\
\hline
\end{tabular}

Sumber : Data primer, 2014

Pada tabel 3 menunjukkan bahwa ibu yang berpenghasilan antara Rp.100.000-500.000 sebanyak 30 orang $(85,7 \%)$ dan ibu yang berpenghasilan kurang dari Rp.100.000/bulan sebanyak 1 orang $(2,9 \%)$.

Tabel 4 Distribusi Frekuensi Ibu Berdasarkan Usia di Puskesmas Pangarengan Bulan Mei Tahun 2014. Umur Frekuensi Persentase $<20$ $9 \quad 25,7$

$21-30 \quad 16 \quad 45,7$

$>30 \quad 10 \quad 28,6$

$\begin{array}{lll}\text { Total } & 35 & 100\end{array}$

Berdasarkan tabel 4 dapat dilihat bahwa ibu yang terbanyak yaitu ibu berusia 20-30 tahun sebanyak 16 orang $(45,7 \%)$ dan paling sedikit adalah ibu berusia <20 tahun sebanyak 9 orang $(25,7 \%)$.

Tabel 5 Distribusi Frekuensi lbu Berdasarkan Personal Hygiene di Puskesmas Pengarengan Bulan Mei Tahun 2014

\begin{tabular}{lccc}
\hline \multicolumn{2}{l}{ Personal Hygiene } & Frekuensi & Persentase \\
\hline $\begin{array}{l}\text { Personal } \\
\text { kurang }\end{array}$ & Hygiene & 2 & 5,7 \\
\hline $\begin{array}{l}\text { Personal } \\
\text { cukup }\end{array}$ & Hygiene & 9 & 25,7 \\
\hline $\begin{array}{l}\text { Personal } \\
\text { baik }\end{array}$ & Hygiene & 24 & 68,6 \\
\hline \multicolumn{1}{c}{ Total } & $\mathbf{3 5}$ & $\mathbf{1 0 0}$ \\
\hline
\end{tabular}


Berdasarkan tabel 5 menunjukkan bahwa personal hygiene ibu paling banyak personal hygiene baik sebanyak 24 orang $(68,6 \%)$ dan ibu yang personal hygiene kurang sebanyak 2 orang $(5,7 \%)$.

Tabel 6 Distribusi Frekuensi Ibu Berdasarkan Penyembuhan Luka Perineum di Puskesmas Pangarengan Bulan Mei Tahun 2014

\begin{tabular}{lcc}
\hline $\begin{array}{l}\text { Penyembuhan } \\
\text { Luka Perineum }\end{array}$ & Frekuensi & $\begin{array}{c}\text { Persentase } \\
(\%)\end{array}$ \\
\hline Luka buruk & 2 & 5,7 \\
\hline Luka sedang & 9 & 25,7 \\
\hline Luka baik & 24 & 68,6 \\
\hline Total & $\mathbf{3 5}$ & $\mathbf{1 0 0}$ \\
\hline
\end{tabular}

Tabel 6 menunjukkan bahwa sebagian besar luka baik sebanyak 24 orang $(68,6 \%)$ dan sebagian kecil penyembuhan luka buruk sebanyak 2 orang $(5,7 \%)$.

\section{Analisis Bivariat}

Tabel 7 Hasil Tabulasi Silang Hubungan pengetahuan lbu dengan penyembuhan luka perineum di Puskesmas Pangarengan Bulan Mei 2014.

\begin{tabular}{lccccccccc}
\hline \multirow{2}{*}{$\begin{array}{c}\text { Penget } \\
\text { ahuan }\end{array}$} & \multicolumn{4}{c}{$\begin{array}{c}\text { Penyembuhan luka } \\
\text { perineum }\end{array}$} \\
\cline { 2 - 9 } & $\begin{array}{c}\text { Luka } \\
\text { buruk }\end{array}$ & $\begin{array}{c}\text { Luka } \\
\text { sedang }\end{array}$ & \multicolumn{2}{c}{$\begin{array}{c}\text { Luka } \\
\text { Baik }\end{array}$} & & \\
& $\mathbf{N}$ & $\%$ & $\mathbf{N}$ & $\%$ & $\mathbf{N}$ & $\%$ & $\mathbf{N}$ & $\%$ \\
\hline Kurang & 2 & 5,7 & 0 & 0 & 1 & 2,9 & 3 & 8,6 \\
\hline Cukup & 0 & 0 & 3 & 8,6 & 7 & 20 & 10 & 28,6 \\
\hline Baik & 0 & - & 6 & 17,1 & 16 & 45,7 & 22 & 62,9 \\
\hline Total & $\mathbf{2}$ & $\mathbf{5 , 7}$ & $\mathbf{9}$ & $\mathbf{2 5 , 7}$ & $\mathbf{2 4}$ & $\mathbf{6 8 , 6}$ & $\mathbf{3 5}$ & $\mathbf{1 0 0}$ \\
\hline
\end{tabular}

Pada tabel 7 dari 35 ibu yang sebagian besar berpengetahuan baik dengan luka baik sebanyak 16 orang $(45,7 \%)$ dan ibu yang berpengetahuan cukup dengan luka baik sebanyak 7 orang $(20 \%)$ Sedangkan sebagian kecil ibu yang berpengetahuan kurang dengan luka baik sebanyak 1 orang (33,3\%).

Tabel 8 Hasil Tabulasi Silang Hubungan Status Gizi Ibu dengan penyembuhan luka perineum di Puskesmas Pangarengan Bulan Mei 2014. Penyembuhan luka

\begin{tabular}{cccccccccc}
\multirow{2}{*}{$\begin{array}{c}\text { Status } \\
\text { Gizi }\end{array}$} & \multicolumn{4}{c}{ Penyembuhan luka } & \multirow{2}{*}{ Jumlah } \\
\cline { 2 - 6 } & $\begin{array}{c}\text { Luka } \\
\text { buruk }\end{array}$ & \multicolumn{3}{c}{ Luka } \\
& sedang & \multicolumn{2}{c}{ Luka } \\
Baik & & \\
\cline { 2 - 6 } & $\mathbf{N}$ & $\%$ & $\mathbf{N}$ & $\%$ & $\mathbf{N}$ & $\%$ & $\mathbf{N}$ & $\%$ \\
\hline $\begin{array}{c}\text { Sangat } \\
\text { kurus }\end{array}$ & 0 & 0 & 0 & 0 & 1 & 2,9 & 1 & 2,9 \\
\hline Kurus & 0 & 0 & 2 & 5,7 & 3 & 8,6 & 5 & 14,3 \\
\hline Normal & 2 & 5,7 & 6 & 17,1 & 14 & 40 & 22 & 62,9 \\
\hline Gemuk & 0 & 0 & 1 & 2,9 & 3 & 8,6 & 4 & 11,4 \\
\hline Sangat & 0 & 0 & 0 & 0 & 3 & 8,6 & 3 & 2,9 \\
Gemuk & & & & & & & & \\
\hline Total & $\mathbf{2}$ & $\mathbf{5 , 7}$ & $\mathbf{9}$ & $\mathbf{2 5 , 7}$ & $\mathbf{2 4}$ & $\mathbf{6 8 , 6}$ & $\mathbf{3 5}$ & $\mathbf{1 0 0}$ \\
\hline
\end{tabular}

Tabel 8 menunjukkan bahwa dari 35 ibu sebagian besar status gizinya normal dengan luka baik sebanyak 14 orang (40\%) dan sebagian kecil status gizi sangat kurus dengan luka baik sebanyak 1 orang $(2,9 \%)$.

Tabel 9 Hasil Tabulasi Silang Hubungan pendapatan dengan penyembuhan luka perineum di Puskesmas Pangarengan Bulan Mei 2014. 


\begin{tabular}{|c|c|c|c|c|c|c|c|c|}
\hline \multirow{3}{*}{$\begin{array}{c}\text { Pendapat } \\
\text { an }\end{array}$} & \multicolumn{6}{|c|}{$\begin{array}{c}\text { Penyembuhan luka } \\
\text { perineum }\end{array}$} & \multicolumn{2}{|c|}{ Total } \\
\hline & \multicolumn{2}{|c|}{$\begin{array}{l}\text { Luka } \\
\text { buruk }\end{array}$} & \multicolumn{2}{|c|}{$\begin{array}{l}\text { Luka } \\
\text { sedang }\end{array}$} & \multicolumn{2}{|c|}{$\begin{array}{l}\text { Luka } \\
\text { Baik }\end{array}$} & \multirow[b]{2}{*}{$\mathbf{N}$} & \multirow[b]{2}{*}{$\%$} \\
\hline & $\mathbf{N}$ & $\%$ & $\mathbf{N}$ & $\%$ & $\mathbf{N}$ & $\%$ & & \\
\hline $\begin{array}{c}< \\
\text { Rp. } 100.000\end{array}$ & 0 & 0 & 0 & 0 & 1 & 2.9 & 1 & 2.9 \\
\hline $\begin{array}{l}\text { Rp.100.000 } \\
-500.000\end{array}$ & 2 & 5,7 & 7 & 20 & 21 & 60 & 30 & $\begin{array}{c}85 \\
7\end{array}$ \\
\hline Rp. $\stackrel{>}{>00} .000$ & 0 & 0 & 2 & 5,7 & 2 & 5,7 & 4 & $\begin{array}{c}11 \\
4\end{array}$ \\
\hline Total & 2 & 5,7 & 9 & 25,7 & 24 & 68,6 & 35 & 100 \\
\hline
\end{tabular}

Berdasarkan tabel 9 dari 35 ibu sebagian besar pendapatan antara Rp.100.000-500.000 dengan luka baik sebanyak 21 orang (60\%) dan ibu pendapatannya lebih dari Rp.500.000 dengan luka baik dan sedang masingmasing sebanyak 2 orang (5,7\%) Sedangkan sebagian kecil ibu yang pendapatannya kurang Rp.100.000 dengan luka baik sebanyak 1 orang $(2,9 \%)$.

Tabel 10 Hasil Tabulasi Silang Hubungan Usia lbu dengan penyembuhan luka perineum di Puskesmas Pangarengan Bulan Mei 2014

Penyembuhan luka perineum

\begin{tabular}{ccccccccc}
\cline { 2 - 6 } Usia & \multicolumn{2}{c}{$\begin{array}{c}\text { Luka } \\
\text { buruk }\end{array}$} & \multicolumn{2}{c}{$\begin{array}{c}\text { Luka } \\
\text { sedang }\end{array}$} & \multicolumn{2}{c}{$\begin{array}{c}\text { Luka } \\
\text { Baik }\end{array}$} & & \multirow{2}{*}{ Total } \\
\cline { 2 - 6 } & $\mathbf{N}$ & $\%$ & $\mathbf{N}$ & $\%$ & $\mathbf{N}$ & $\%$ & $\mathbf{N}$ & $\%$ \\
\hline $\begin{array}{c}<20 \\
\text { tahun }\end{array}$ & 0 & 0 & 0 & 0 & 9 & 25,7 & 9 & 25,7 \\
\hline $\begin{array}{c}21-30 \\
\text { tahun }\end{array}$ & 1 & 2,9 & 7 & 20 & 8 & 22,9 & 16 & 45,7 \\
\hline $\begin{array}{c}>31 \\
\text { tahun }\end{array}$ & 1 & 2,9 & 2 & 5,7 & 7 & 20 & 10 & 28,6 \\
\hline Total & $\mathbf{2}$ & $\mathbf{5 , 7}$ & $\mathbf{9}$ & $\mathbf{2 5 , 7}$ & $\mathbf{2 4}$ & $\mathbf{6 8 , 6}$ & $\mathbf{3 5}$ & $\mathbf{1 0 0}$ \\
\hline
\end{tabular}

Tabel 10 menunjukkan dari 35 orang sebagian besar ibu berusia antara 20-30 tahun dengan luka baik sebanyak 8 orang $(22,9 \%)$ dan ibu berusia lebih dari 31 tahun dengan luka baik sebanyak 7 orang (20\%). Sedangkan ibu yang berusia kurang dari 20 tahun dengan luka baik sebanyak 9 orang (25,7\%).

Tabel 11 Hasil Tabulasi Silang Hubungan Personal Hygiene lbu dengan penyembuhan luka perineum di Puskesmas Pangarengan Bulan Mei 2014.

Penyembuhan luka

\begin{tabular}{cccccccccc} 
& \multicolumn{4}{c}{ perineum } & \multicolumn{2}{c}{ Total } \\
\cline { 2 - 9 } $\begin{array}{c}\text { Personal } \\
\text { Hygiene }\end{array}$ & $\begin{array}{c}\text { Luka } \\
\text { buruk }\end{array}$ & $\begin{array}{c}\text { Luka } \\
\text { sedan } \\
\mathbf{g}\end{array}$ & $\begin{array}{c}\text { Luka } \\
\text { Baik }\end{array}$ & & \\
\cline { 2 - 9 } & $\mathbf{N}$ & $\%$ & $\mathbf{N}$ & $\%$ & $\mathbf{N}$ & $\%$ & $\mathbf{N}$ & $\%$ \\
\hline Kurang & 2 & 5,7 & 0 & 0 & 0 & 0 & 2 & 5,7 \\
\hline Cukup & 0 & 0 & 6 & 17,4 & 3 & 8,6 & 9 & 25,7 \\
\hline Baik & 0 & 0 & 3 & 8,6 & 21 & 60 & 24 & 68,6 \\
\hline Total & $\mathbf{2}$ & $\mathbf{5 , 7}$ & $\mathbf{9}$ & $\mathbf{2 5 , 7}$ & $\mathbf{2 4}$ & $\mathbf{6 8 , 6}$ & $\mathbf{3 5}$ & $\mathbf{1 0 0}$ \\
\hline
\end{tabular}

Tabel 11 menunjukkan dari 35 orang sebagian besar personal hygiene ibu baik dengan luka baik sebanyak 21 orang $(60 \%)$ dan personal hygiene ibu cukup dengan luka sedang sebanyak 6 orang $(17,4 \%)$. Sedangkan personal hygiene ibu kurang dengan luka buruk sebanyak 2 orang (15,7\%).

Tabel 12 Analisis Korelasi Spearman Rank Faktor-Faktor Yang Mempengaruhi Penyembuhan Luka Perineum di Puskesmas Pangarengan Kec. Pangarengan Kab. Sampang. 


\begin{tabular}{|c|c|c|}
\hline Variabel & Nilai Sig & $\mathrm{Ha} / \mathrm{Ho}$ \\
\hline Pengetahuan & 0.216 & $\begin{array}{c}\mathrm{HO} \text { diterima, } \mathrm{Ha} \\
\text { ditolak }\end{array}$ \\
\hline Status Gizi & 0.717 & $\begin{array}{c}\text { HO diterima, } \mathrm{Ha} \\
\text { ditolak }\end{array}$ \\
\hline Pendapatan & 0.376 & $\begin{array}{c}\text { HO diterima, } \mathrm{Ha} \\
\text { ditolak }\end{array}$ \\
\hline Usia & 0.185 & $\begin{array}{c}\text { HO diterima, } \mathrm{Ha} \\
\text { ditolak }\end{array}$ \\
\hline $\begin{array}{l}\text { Personal } \\
\text { Hygiene }\end{array}$ & 0.000 & $\begin{array}{c}\text { H0 ditolak, } \mathrm{Ha} \\
\text { diterima }\end{array}$ \\
\hline
\end{tabular}

Berdasarkan tabel 12, dari lima variabel yang diteliti didapatkan adanya pengaruh personal hygiene dalam penyembuhan luka perineum pada ibu nifas di Puskesmas Pangarengan Kecamatan Pangarengan Kabupaten Sampang.

\section{PEMBAHASAN}

\section{A. Analisis Univariat}

\section{Pengetahuan ibu Nifas}

Berdasarkan tabel 1 didapatkan sebagian besar ibu berpengetahuan baik sebanyak 22 orang (62.9\%). Peneliti berasumsi bahwa semakin luas pengetahuan seseorang maka seseorang akan dapat melakukan suatu tindakan yang sesuai dengan kepentingannya sehingga ibu nifas akan melakukan perawatan luka perineum dengan baik.

\section{Status Gizi lbu Nifas}

Berdasarkan tabel 2 sebagian besar ibu memiliki status gizi normal, yaitu sebanyak 22 orang (62.8\%). Peneliti berasumsi bahwa status gizi diperoleh dari apa yang dimakan oleh ibu pada waktu masa nifas dengan menu makanan yang mengandung cukup gizi dan tidak melakukan pantang makanan sehingga pada saat masa nifas ibu gizi ibu tetap normal.

Menurut Smeltzer (2002), makanan yang bergizi dan sesuai porsi akan menyebabkan ibu dalam keadaan sehat dan segar serta akan mempercepat masa penyembuhan luka perineum. Kualitas dan jumlah makan yang dikonsumsi ibu sangat berpengaruh pada penyembuhan luka jalan lahir.

\section{Pendapatan Ibu Nifas}

Berdasarkan tabel 3 paling banyak ibu berpenghasilan antara Rp.100.000-500.000, yaitu sebanyak 30 orang (85.7\%). Peneliti berpendapat bahwa pendapatan seseorang akan mempengaruhi apa yang menjadi keputusan dalam menentukan perawatan luka perinuem dengan baik.

Menurut Mahmud (2003), pendapatan adalah sebagai jumlah dari semua pendapatan yang diterima oleh segenap golongan masyarakat yang ikut dalam memproduksi barang dan jasa, baik berupa upah atau gaji. 
4. Usia Ibu Nifas

Pada tabel 4 dapat dilihat bahwa ibu yang terbanyak yaitu ibu berusia 20-30 tahun sebanyak 16 orang $(45.7 \%)$.

Kematangan usia ibu berpengaruh penting dalam setiap menentukan keputusan dan tindakan ibu dalam melakukan perawatan luka perinuem dengan baik sehingga dapat membantu mempercepat proses penyembuhan luka perineum dengan baik dalam kurun waktu kurang dari 7 hari. Usia akan berpengaruh terhadap penyembuhan luka perenium pada sebagian besar ibu. Tingkat usia akan mempengaruhi pola hidup seseorang terutama dalam memotivasi untuk berperan serta dalam kehidupan sehari-hari.

\section{Personal Hygiene Ibu Nifas}

Tabel 5 menunjukkan bahwa personal hygiene ibu yang paling banyak, yaitu personal hygiene baik sebanyak 24 orang (68.6\%). Peneliti berasumsi bahwa baiknya kesembuhan luka perineum ibu dan baiknya personal hygiene ibu dikarenakan ibu sudah mengerti dan mengetahui tentang manfaat dari personal hygiene.

6. Penyembuhan Luka Perineum Ibu Nifas
Tabel 6 menunjukkan bahwa penyembuhan luka perineum sebagian besar luka baik sebanyak 24 orang (68.6\%).

Pernyembuhan luka adalah suatu proses upaya perbaikan jaringan. Proses penyembuhan luka dapat kita kelompokkan dalam 3 fase; fase inflamasi, fase proliferasi dan fase remodeling. Selain perlakuan jaringan luka, faktor lain juga sangat berpengaruh pada penyembuhan luka seperti ras, genetik, lokasi luka, berbagai hal yang menyebabkan waktu penyembuhan luka menjadi lama.

\section{B. Analisis Bivariat}

1. Menganalisis Pengetahuan Ibu Dalam Penyembuhan Luka Perineum

Berdasarkan tabel 7 dari 35 ibu sebagian besar berpengetahuan baik dengan luka baik sebanyak 16 orang (45.7\%). Sedangkan sebagian kecil ibu yang berpengetahuan kurang dengan luka baik sebanyak 1 orang (33.3\%). Berdasarkan hasil uji Korelasi Spearman Rank didapatkan $\rho=0.214$ yang artinya $\rho(0.214)>\alpha$ $(0,05)$ maka HO diterima yang artinya tidak ada pengaruh antara pengetahuan dengan penyembuhan luka perineum.

Dalam hal ini hasil dari penelitian bahwa pengetahuan yang 
baik tidak berpengaruh terhadap penyembuhan luka perineum disebabkan karena adanya faktor lain seperti personal hygiene yang baik, status gizi ibu, dukungan dari keluarga, pengalaman ibu nifas dalam perawatan luka perineum. Sedangkan pengetahuan yang baik belum tentu juga melakukan perawatan luka perineum dengan baik sehingga dalam memperlambat proses penyembuhan luka perineum.

2. Menganalisis Status Gizi lbu Dalam Penyembuhan Luka Perineum

Tabel 8 menunjukkan bahwa dari 35 ibu sebagaian besar status gizinya normal dengan luka baik sebanyak 13 orang (37.1\%) dan sebagian kecil status gizi sangat kurus dengan luka baik sebanyak 1 orang (2.9\%). Berdasarkan hasil uji Korelasi Spearman Rank didapatkan $\rho=0.717$ yang artinya $\rho(0.717)<\alpha$ (0.05) maka HO diterima, yang artinya tidak ada pengaruh antara status gizi dengan penyembuhan luka perineum.

Peneliti berasumsi, bahwa dari sebagian ibu nifas masih melakukan pantang makanan, seperti ibu hanya makan makanan tertentu saja. Jika seorang ibu mempunyai sikap yang baik terhadap gizi maka akan melahirkan perilaku yang baik pula dalam meningkatkan status gizinya, namun pada kenyataannya sering kali sikap tidak sejalan dengan tindakan. Hal ini mungkin dipengaruhi faktor lain seperti pengalaman dalam merawat luka perineum.

\section{Menganalisis Pendapatan lbu Dalam Penyembuhan Luka Perineum}

Berdasarkan tabel 9 dari jumlah total 35 ibu, sebagian besar memiliki pendapatan antara Rp.100.000500.000 dengan luka baik sebanyak 21 orang (60\%) dan ibu yang pendapatannya lebih dari Rp.500.000 dengan luka baik dan sedang masing-masing sebanyak 2 orang $(5.7 \%)$. Sedangkan sebagian kecil ibu yang pendapatannya kurang dari Rp.100.000 dengan luka baik sebanyak 1 orang (2.9\%). Berdasarkan hasil uji Korelasi Spearman Rank didapatkan bahwa variabel pendapatan menghasilkan: $\rho=0.376$ yang artinya $\rho(0.376)>\alpha$ (0.05) maka HO diterima hal ini dapat disimpulkan bahwa pendapatan tidak ada pengaruh antara pendapatan dengan penyembuhan luka perineum.

Pendapatan ibu yang rendah tidak berpengaruh dalam proses penyembuhan luka perineum. Pada 
masyarakat selain yang berpenghasilan rendah, mereka mempunyai lahan yang dapat dimanfaatkan seoptimal mungkin dan dapat menghasilkan sumber pangan sehingga dapat memenuhi kebutuhan keluarganya seperti status gizinya. Dengan status gizi yang baik proses penyembuhan luka dapat dengan baik, pengalaman dalam merawat luka, sehingga faktor status ekonomi tidak berpengaruh terhadap proses penyembuhan luka perineum.

\section{Menganalisis Usia Ibu Dalam}

\section{Penyembuhan Luka Perineum}

Berdasarkan tabel 10 didapatkan dari 35 orang sebagian besar ibu berusia antara 21-30 tahun dengan luka baik sebanyak 8 orang $(22.9 \%)$ dan ibu berusia lebih dari 31 tahun dengan luka baik sebanyak 7 orang (20\%).

Sedangkan ibu yang berusia kurang dari 20 tahun dengan luka baik sebanyak 9 orang (25.7\%). Berdasarkan hasil Korelasi uji Spearman Rank didapatkan $\rho=$ 0.185 yang artinya $\rho(0.185)<\alpha$ $(0,05)$ maka HO diterima yang artinya tidak ada pengaruh antara usia dengan penyembuhan luka perineum. Peneliti berasumsi usia tidak berpengaruh dengan penyembuhan luka perineum karena usia bukan syarat mutlak untuk mempercepat penyembuhan luka perineum. Penyembuhan luka perineum memiliki banyak faktor yang mempengaruhi, diantaranya faktor pengetahuan, pengalaman, status gizi, pendapatan, personal hygiene tetapi yang sangat penting adalah cara perawatan.

Creasoft (2002) berpendapat bahwa kesembuhan luka perineum dipengaruhi oleh beberapa faktor antara lain faktor internal, yaitu usia, dimana penyembuhan luka lebih cepat terjadi pada usia muda dari pada orang tua. Orang yang sudah lanjut usianya tidak dapat mentolerir stres seperti trauma jaringan atau infeksi.

\section{Menganalisis Personal Hygiene} Ibu Dalam Penyembuhan Luka

\section{Perineum}

Berdasarkan tabel 11 didapatkan dari 35 orang sebagian besar ibu berusia antara 21-30 tahun dengan luka baik sebanyak 8 orang $(22.9 \%)$ dan ibu berusia lebih dari 31 tahun dengan luka baik sebanyak 7 orang (20\%). Sedangkan ibu yang berusia kurang dari 20 tahun dengan luka baik sebanyak 9 orang (25.7\%). Dari hasil uji Korelasi Spearman Rank didapatkan $\rho=0,000$ yang artinya $\rho$ $(0,000)>\alpha(0,05)$ maka HO ditolak, 
yang artinya ada pengaruh antara personal hygiene dengan penyembuhan luka perineum. Jadi personal hygiene yang kurang dapat memperlambat penyembuhan, hal ini dapat menyebabkan adanya benda asing seperti debu dan kuman.

\section{KESIMPULAN DAN SARAN}

Berdasarkan hasil penelitian yang sudah dilakukan dapat disimpulkan bahwa rata-rata pada ibu nifas dengan personal hygiene yang baik memiliki proses penyembuhan luka perineum yang baik. Upaya yang dilakukan untuk penyembuhan luka perineum dengan memberi konseling atau penyuluhan tentang penyembuhan luka perineum.

\section{DAFTAR PUSTAKA}

Ambarawati, E. R. (2009). Asuhan Kebidanan Nifas. Yogyakarta: Mitra Cendikia Press.

Boyle, Maureen. (2008). Pemulihan Luka. Jakarta: EGC

Bahiyatun, 2009. Buku Ajar Asuhan Kebidanan Nifas Normal. Jakarta: EGC

Hidayat, A. A. 2007. Metode Penelitian Keperawatan dan Teknik Analisis

Nursalam. (2011). Konsep Dan Penerapan Metodologi Penelitian IImu Keperawatan. Salemba Medika. Jakarta.
Mas'adah, dkk. (2010). Jurnal Penelitian Kesehatan Suara Forikes. http://isjd.pdii.lipi.go.id (di akses tanggal 20 Januari 2014).

Mochtar, R. (1998). Sinopsis Obstetri Fisiologi, Obstetri Patologi. Jakarta: EGC

Prawirohardjo, S., (2005). IImu kebidanan. Jakarta: Yayasan Bina Pustaka.

Rismawanti, et al. (2012). Hubungan Antara Sikap Ibu Nifas Terhadap Makanan Gizi Seimbang Dengan Penyembuhan Luka Perineum Di Klinik Bersalin Khairunnisa. Bidan Prada : Jurnal IImiah Kebidanan, Vol.3 No.1 Edisi Juni 2012.

Saifuddin, et al., (2006). Buku Acuan

Nasional Pelayanan Kesehatan

Maternal Dan Neonatal. Jakarta:

Yayasan Bina Pustaka Sarwono

Prawiroharjo.

Saleha, Siti. (2009). Asuhan Kebidanan Pada Masa Nifas. Jakarta Salemba:Medika

Smeltzer S. C. (2002). Buku ajar

keperawatan medikal bedah. EGC.

Jakarta

Uliyah, (2008). Keterampilan Dasar Praktik

Klinik Kebidanan. Jakarta: Salemba Empat

Wiknjosastro Hanifah. (2008). Ilmu Bedah Kebidanan. Jakarta: PT Bina Pustaka Sarwono Prawiroharjo 